\title{
Conjugal violence in the perspective of "Family Health Strategy" professionals: a public health problem and the need to provide care for the women
}

\author{
Nadirlene Pereira Gomes ${ }^{1}$ \\ Alacoque Lorenzini Erdmann²
}

Objective: to construct a theoretical matrix based on the meanings of the interactions and actions experienced by the professionals regarding the nursing care practices and the health of women in situations of conjugal violence in the ambit of the Family Health Strategy. Methods: research based in Grounded Theory. Following approval by the Research Ethics Committee, 52 professionals were interviewed in Santa Catarina, Brazil. The analysis was based on open, axial and selective codifications. Results: the theoretical model was delimited based on the phenomenon "Recognizing conjugal violence as a public health problem, and the need for management of the care for the woman", which reflects the experience of the professionals in relation to care for the woman, as well as the meanings attributed to this care. Conclusions: the phenomenon allows one to understand the movement of action and interaction regarding the care for the woman in a situation of conjugal violence.

Descriptors: Violence Against Women; Family Health; Comprehensive Health Care; Nursing; Delivery of Health Care.

\footnotetext{
${ }^{1} \mathrm{PhD}$, Adjunct Professor, Escola de Enfermagem, Universidade Federal da Bahia, Salvador, BA, Brazil. Scholarship holder from Fundação de Amparo à Pesquisa do Estado da Bahia (FAPESB).

${ }^{2}$ PhD, Full Professor, Departamento de Enfermagem, Centro de Ciências da Saúde, Universidade Federal de Santa Catarina, Florianópolis, SC, Brazil.
}

Copyright (c) 2014 Revista Latino-Americana de Enfermagem This is an Open Access article distributed under the terms of the Creative Commons Attribution Non-Commercial License (CC BY-NC).

This license lets others distribute, remix, tweak, and build upon your work non-commercially, and although their new works must also acknowledge you and be non-commercial, they don't have to license their derivative works on the same terms. 


\section{Introduction}

Domestic violence is a violation of human rights, with important repercussions for women's health and economic productivity, which makes violence against women a widely discussed problem in the health area and an issue that has been researched worldwide since the late 1980s. Violence against women is considered to be the action or omission, based on gender inequality, which generates physical, sexual, psychological or property damage ${ }^{(1)}$. The notion of gender was introduced in the United States in the field of Anthropology and paved the way for comprehending the inequalities between men and women, overcoming the view that the attributes and roles, defined based on biological aspects, are natural and unquestionable. The category of gender has become widely used, denouncing patriarchal power, its effects of oppression of women, and the consequent gender violence, especially that which occurs within the home ${ }^{(2-3)}$.

The repercussions of the experience of domestic violence have already been identified in scientific studies. Women who experience it present more health problems, of varying dimensions and complexities, ranging from physical injuries, such as bruises, to injuries related to the psycho-emotional aspects, such as depression and suicide ${ }^{(4-5)}$. Analyzing expenditures of the Brazilian National Health System (SUS) and also the costs surrounding the legal political processes and sick leave due to the violence, the damage of violence against women represents approximately $10 \%$ of the Brazilian Gross Domestic Product (GDP) ${ }^{(6)}$.

Considering that the experience of violence significantly affects the health-disease process of women, the healthcare sector represents a privileged locus for identifying these situations. In this context, professionals must be prepared to identify the phenomenon, which does not always leave visible marks ${ }^{(7)}$. Comprehending violence as an issue of health and for health, the Family Health Strategy (FHS) represents the point of entry for cases of violence, and may be configured as a space of welcome, with projects designed to support women in situations of violence(5).

Studies confirm that the FHS, due to its broad coverage and bond, favors the identification of harm to the health of the population, revealing itself as a strategic scenario for the recognition of domestic violence in the context of the community. However, a study conducted with professionals working in Family Health showed that although many of the complaints of women are associated with the experience of violence, the professionals had difficulty recognizing such harm and knowing how to proceed regarding people in situations of violence(8-11).

The Ministry of Health recognizes the importance of the FHS in the process of identifying women experiencing domestic violence and also states that the link established between people/families/groups and professionals/teams encourages the constructing of relationships of affectivity and trust between the user and the healthcare workers, which facilitates health promotion and harm prevention ${ }^{(12)}$. In this sense, the question is: What are the meanings of the interactions and actions experienced by professionals in relation to the practices of nursing and healthcare for women in situations of domestic violence in the context of the FHS? Considering this, the study aimed to: Construct a theoretical matrix from the meanings of the interactions and actions experienced by the professionals in relation to the practices of nursing and healthcare for women in situations of domestic violence in the context of the FHS.

\section{Methods}

This was a qualitative study, using the methodological framework of Grounded Theory(GT)(13). This methodology aims to systematically and concurrently identify, develop and relate concepts/categories from the data collected, analyzed and compared, in order to construct an explanatory theoretical framework of a social phenomenon ${ }^{(13-14)}$. Based on GT, it was sought to explore the diversity of the experience of the health professionals working in the FHS and thus to amplify the understanding of the care to the woman in situations of domestic violence, in order to provide subsidies for coping actions for the phenomenon.

The study was conducted with 52 professionals working in the 17 family health teams that comprise the five health units of a particular Health District of a municipality in the state of Santa Catarina, Brazil. As recommended by GT, the inclusion of subjects was performed according to the principles of theoretica sampling. The first sample group consisted of nursing technicians (17), nurses (13) and physicians (12), aiming to obtain answers to the question: How is care provided to women in situations of domestic violence within the context of the FHS? The analysis of the data was concurrent with the data collection and allowed the codes and categories to be discovered. Given the absence 
of new data, we considered that theoretical saturation had been reached, after a total of 42 interviews.

The initial analysis codes revealed that cases of domestic violence identified in the FHS are referred to psychiatrists, psychologists and social workers from the Family Health Support Center (NASF), a situation that directed us to new questions to be investigated. In this sense, the second sample group was composed of psychologists (02), social workers (01) and psychiatrists (02) in order to better understand the process of care to the woman by these professionals. All the psychologists, psychiatrists and social workers that composed the NASF of the health district selected as the study locus were interviewed. The data analysis indicated the limited availability of these professionals, a situation that limits the healthcare and health promotion actions. The third sample group was composed of the five coordinators of the health facilities in order to better comprehend the reality of this care, especially in relation to the management. The analysis of data supported the previously identified categories.

At the same time as the interviews were conducted and transcribed, the data were entered into the NVivo ${ }^{\circledR}$ program, which enabled the organization and classification of the collected information. The substantive analysis of the data was performed through open coding, axial coding and selective coding. This was based on the paradigm of data analysis proposed by Strauss and Corbin, from the five structural concepts: context, causal conditions, intervening conditions, strategies, and consequences. The relationships, associations and interactions between these categories take place until the central category is defined, representative of the phenomenon of study ${ }^{(13)}$. The validation of the paradigmatic model was performed with 37 research subjects in the five health units studied and with ten researchers with experience in GT.

The project, funded by FAPESB, was approved the Research Ethics Committee (No.21560/2012). Interviews were conducted from May to August 2012, in the physical space of the units in a closed room, to ensure the privacy of the subjects. These were identified by the initial letters of the professional category, e.g. the letter $\mathrm{C}$ in the case of coordinators, Pg for psychologists, and Pt for psychiatrists, followed by a number.

\section{Results}

The categories that represent the elements of the paradigmatic model, which allowed the central phenomenon to emerge, are presented below:

\section{Phenomenon}

The theoretic model was delimited from the phenomenon "Recognizing domestic violence as a public health problem and the need for management of the care to the woman", which reflects the experience of the professionals who work in the FHS in relation to care to the woman and the meanings attributed to this care (Figure 1).

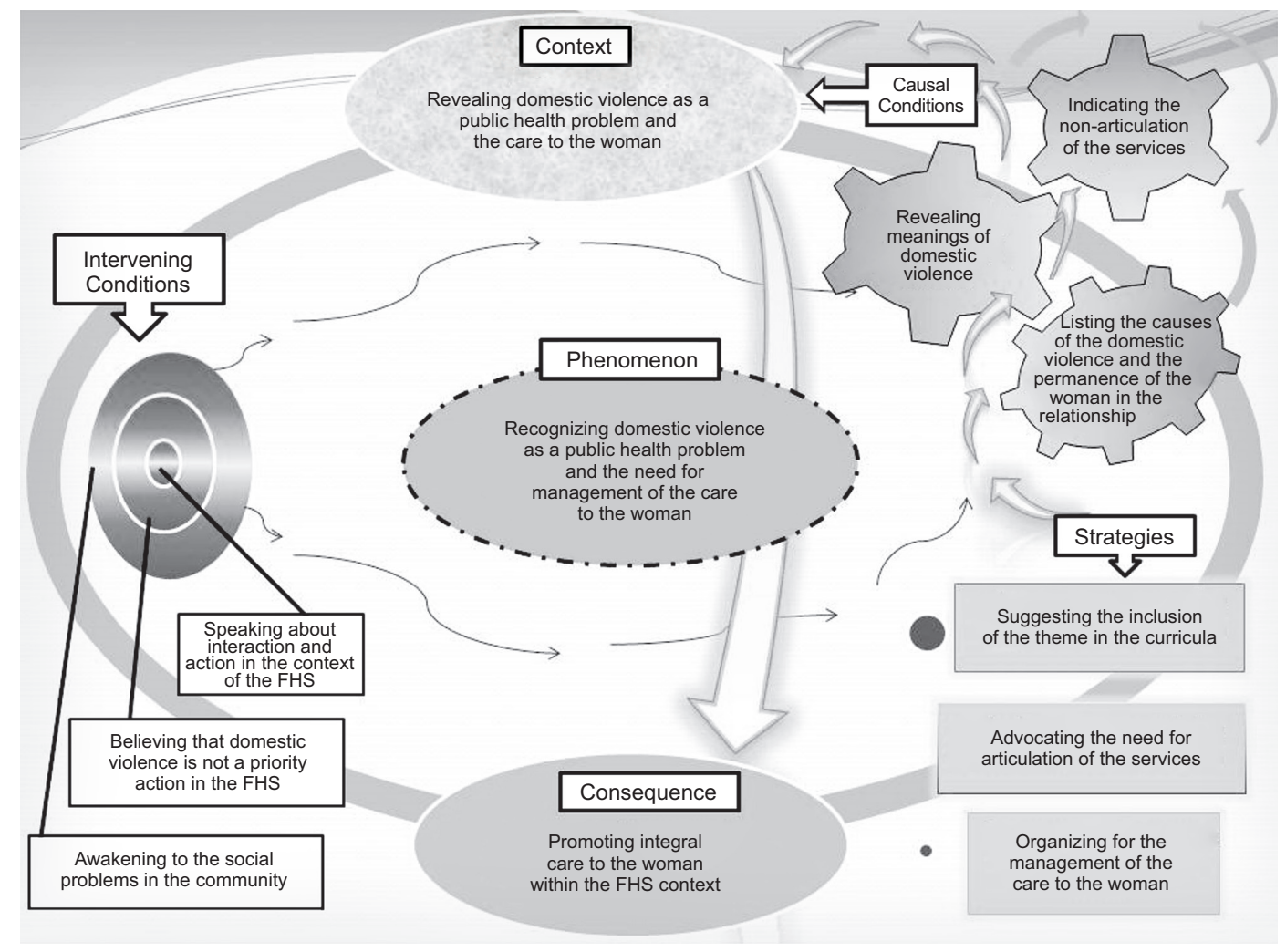

Figure 1 - Theoretic model of the Substantive Theory 
Considering that the phenomenon represents the central event in relation to a set of actions or interactions performed by the subjects, this indicates what is happening ${ }^{(14)}$. Thus, the professionals interviewed understood domestic violence to be an important harm to the health of the woman, with implications for the healthcare sector and economic productivity. They perceived the need, as health units, to be better prepared for the care to the woman, which involves the recognition of domestic violence as a cause associated with them seeking the service and the care itself. This complex phenomenon is in motion and configures itself in the dynamics of the interactions of knowledge, actions and articulations directed toward promoting integral care to the woman.

The categories that constituted the paradigmatic model, enabling the emergence of the phenomenon, were: context, causal conditions, intervening conditions, action strategies, and consequences.

\section{Context}

Context is understood as the specific set of events, facts or conditions related to the phenomenon, from which the strategies of action/interaction are defined(14). The phenomenon has, as the context, the category "Revealing domestic violence as a public health problem and the care to the woman", which includes the following subcategories:

\section{Revealing meanings of domestic violence}

The professionals who work in the FHS comprehended that domestic violence causes repercussions for women and impacts in the lives of the children and in the economic productivity: [...] physical, psychic it is all one thing. There is often somatization. (Pg-2); I attended a marital problem case that ended up triggering a psychiatric crisis [...] she was very depressed [...]. She was not working. (Pt-1); [...] sometimes you see your father beating your mother throughout your entire life and you think that it is normal and you will pick this up and you will beat women. [...] this can lead to a death, a murder, something worse. It is a public health problem [...] due to not going to work, decreasing the productivity. (Ph-4)

Describing the care process for the women

The professionals of the minimum team, when identifying women in situations of violence, refer them to psychologists and social workers of the NASF. By being linked to various health units, such professionals can not meet the demand, which compromises the care for the women: We are open for all kinds of care, but it is not something that we experienced here. (Ph-1); This part of violence is handled more by social workers and psychologists, and always continues with the nurse and the physician who coordinate the care and have to know what everyone is doing and we end up having meetings with all them. (Ph-3); One difficulty I see is for us of the NASF, we can not be in the unit all the time. [...] the proposal is to promote, but it ends up that at times I'm on the other side of the care. And in our case, care more focused on support because it is still subdivided. (Pg-2)

Based on the above, the context "Revealing domestic violence as a public health problem and the care to the woman" shows that the professionals working within the context of the FHS comprehend domestic violence as significant harm to the lives of the women, as well as their children. The professionals of the minimum team said that cases of domestic violence were not frequent within the FHS, indicating the low visibility of the phenomenon in the community. It is noteworthy that, when identifying women in this context, they refer them for psychosocial support from the NASF. However, the limited availability of psychologists and social workers does not allow the needs of the users to be fulfilled.

\section{Causal Conditions}

The causal conditions consist of events, facts or developments that influence the phenomenon and are associated with its occurrence or development ${ }^{(14)}$. Three categories reflect the causal conditions. These are:

Listing the causes of the domestic violence and the permanence of the woman in the relationship

The professionals mentioned that the construction of domestic violence is associated with the use of alcohol or drugs by the partner: I think that what leads to violence between the couple is the use of drugs such as alcohol or cocaine. $(\mathrm{N}-13)$

The economic situation was perceived as a reason to stay in the relationship with the partner: The person does not have money, she has school-age children [...] if she separates from the partner, it will be more difficult for her to manage to raise the children. (N-11)

Drug dealing in the communities was also cited by the professionals, who consider the involvement of the man in selling drugs as a situation that favors the silence of the women: Normally, the person does not speak because they are involved with drug dealing and know that if they open their mouth there will be retaliation and the problem will become much greater. (Ph-5) 
The social construction anchored in gender inequality, responsible for the naturalization of the power of the man over the woman and for the belief of marriage as a female achievement, was identified as the cause associated with the occurrence of violence and the permanence of the women in the relationship: It is a relationship in which she has the idea that this is normal: the relationship of husband and wife is like that. (C-2); [...] she is in a bond of dependency that the other will provide anything for her, however, she thinks she cannot live alone. Then, she is subject to this situation. ( $\mathrm{Pg}-1)$

Revealing the lack of preparation of the professionals for the care to the woman

This category reveals that the professionals felt unprepared for the care of women in situations of domestic violence, which permeates the recognition of the harm, referrals, knowledge of the services and of the flow, and the reporting of cases. Indicating the limited (if any) coverage of the theme during the graduation. These events are related to the lack of perception of the violence by the professional of the minimum team: We do not have this in the curriculum. [...] Due to the lack of this view, sometimes, the person arrives there, and you do not realize. [...] sometimes there is a great demand from people, who do not report that there is violence. [...] $(\mathrm{N}-5)$; There is notification, but I think it is rarely reported. [...] in some situations, the team stays in the background, not knowing what to do, which direction to follow, which path to take. [...] it ends up as personal support. (C-2)

Indicating the non-articulation of the services

The non-articulation of the services constitutes a situation that compromises the care to the woman: The network does not know how to work very well with violence. I think it is still a little unarticulated. Things get lost a lot: what is the function of one, what is the function of the other, the flows. It is quite difficult to organize and what happens is that everyone ends up lost, nobody knows where to send the person. (C-3)

Considering the categories that comprise the causal conditions, it can be perceived that the professionals attributed gender inequality, economic difficulty, and the reality of drugs to the construction of violence in the marital relationship, as well as the silence of the women and their permanence in the relationship with their partner. The lack of preparation of the professionals interviewed for the care of women in situations of domestic violence was also highlighted, including the need for intersectoral articulation.

\section{Intervening Conditions}

Intervening conditions are considered to be events, circumstances or developments that alter the impact of the causal conditions on the phenomenon, in order to facilitate, hinder or restrict the strategies of action/ interaction in a specific context ${ }^{(14)}$.

The intervening conditions emerged from the integration between three categories, namely:

Speaking about interaction and action in the context of the FHS

The actions and interactions of the professionals can facilitate or restrict the causal conditions. Revealed as a facilitator, the multidisciplinary approach allowed the exchange of knowledge and a broader vision of the reality: Previously I was alone, there was no FHS. The social worker did her job, the nurse did her job. It was more individual, it was not a group. We did not sit together, all the professionals, to discuss. Today, the Family Health Program has a way to sit down and discuss how to help that patient. (N-6)

Believing that domestic violence is not a priority action in the FHS

Prevention actions and coping with domestic violence were not indicated as priorities by the professionals interviewed. They revealed the need for a program to guide the recognition of the harm and the care to the woman in situations of violence; they complained that only one psychologist and one social worker were available for the various teams and units, as well as the consultation time and turnover of the professionals, which compromise the actions in the FHS. These events act on the causal conditions hindering a change of the context: [...] there are program for diabetes, hypertension, but not for violence [...] this would best direct what to do. (NT-8); [...] I believe in this Family Health model, but I don't believe in the proportions of one NASF for so many Family Health Teams. [...] it is absurd. How can a social worker manage to do something and still manage to do health promotion? (Ph-7)

Awakening to the social problems in the community

The professionals realize that in the community there are other social problems, as well as domestic violence. Such problems act on the causal conditions and require psychosocial support: We need psychosocial care for the victims, which may be sexual violence, domestic violence, or moral violence [...] and it is not only the women: there is 
violence against the elderly, children. (N-13); Unfortunately, we have people here who have lost a child due to violence [...] due to drugs; people who need psychotherapy. (Ph-7)

In the view of the respondents, drug dealing, which permeates the communities covered by the health district studied, is configured as an event that interferes with the causal conditions, aggravating the context. Faced with this reality, many professionals seek not to involve themselves. However, professional non-intervention hinders the process of empowerment of the women to cope with the phenomenon: There's no way the healthcare professionals can meddle in the women's lives. It's even risky [...] we live in an area that has violent people, drug dealers. So, nobody meddles. (NT-3); [...] the guy is part of the issue of drug dealing here, which is very strong. So, the professionals themselves are afraid of retaliation and do not report it. $(\mathrm{N}-1)$

The study showed that the various social issues that require psychosocial support and the non-adoption of domestic violence as a basic priority action are situations which hinder the causal conditions. However, the multidisciplinary interaction, especially through matrix support, impacts in a positive way. This set of events is called: intervening conditions.

\section{Strategies}

Strategies consist of interactions or actions carried out, or to be implemented, perceived as pertinent and strategic to perform or respond to a phenomenon(14). In order to modify the context, the following strategies were proposed:

Suggesting the inclusion of the theme in the curricula

The inclusion of the theme of violence against women in the undergraduate curricula, through experience and clinical placements, was thought of as an action that would favor the professional preparation for care to the woman: I think it important to study this in the training [...] the part of experience: of coming to the units, of attending patients in the community, making visits, working with social workers, seeing how the community is, experiencing the care together and within the unit. I think it's important to know what is waiting for you in reality [...] so you can cope and identify because sometimes people do not say anything. (Ph-3)

Advocating the need for articulation of the services

Intersectoral articulation was mentioned as a strategy that facilitates the process of coping with domestic violence, this being a need expressed by the professionals working in the FHS: [...] it is necessary to strengthen a bond between these institutions and the Family Health [...]. I think this is the way. [...] if we had this bond with the sector responsible for women's health, it would help a lot. $(\mathrm{N}-2)$

Organizing for the management of the care to the woman

The organization of the health unit for managing the care to women in situations of violence was also indicated as a strategy. The professionals proposed greater divulgation of the services in which women can seek support, and the presentation of the epidemiological framework of the problem. Being better prepared was already indicated an action, which can occur through instruction, training, discussions in meetings, as well as through partnership with the university: I think that at first this violence data should be shown to the team: how this occurs [...] because from these data, we work through ongoing education bringing elements for the team, better enabling the team to detect this type of situation. (C-5), I think that we, having a time for discussion in monthly meetings, we can discuss what is not working here. (Ph-4), [...] to make a partnership with the support of the universities, with the support of the people who are there performing studies and refining. $(\mathrm{N}-1)$

The inclusion of the domestic violence theme in the curricula of the undergraduate courses, intersectoral articulation, and the management of the unit for the care to women in situations of violence were considered coping strategies for domestic violence.

Given the strategies listed, the study indicates the complexity that permeates the domestic violence theme since the first two categories transcend the local power of resolvability, requiring actions and interactions with different social and institutional segments of local, municipal, state and federal contexts, for the sensitization and implementation of strategies to ensure the inclusion of the theme in the curricula and guarantee intersectoral articulation.

\section{Consequences}

Consequences are understood to be the result or expectations of the action/interaction strategies ${ }^{(14)}$. Therefore, the consequences were represented from the category "Promoting integral care to the woman within the FHS context". The statements below allow us to visualize the meanings attributed by the professionals to the consequences of the strategies for the process of caring for the women in situations of domestic violence: [...] to not take an attitude which in the end will make the situation worse. [...] to learn how to act in these situations, how to cope, how to refer and to know how to approach the women 
too. $(\mathrm{N}-3),[\ldots]$ we must lead her $[. .$.$] so that she doesn't return$ to a situation of aggression again. (NT-1)

It was perceived that if the strategies of action/ interaction proposed by the study were implemented or intensified, the professionals would be better prepared to recognize domestic violence as a cause associated with the woman's requirements for healthcare services in any area of interaction with the user, in the consultations, in educational activities, etc. They will also be more prepared to care for the women, which requires reporting suspected and confirmed cases, referrals for the women considering their requirements, and the monitoring of the cases. To be prepared to recognize the harm and the treatment for the women can empower them to cope with the violence experienced in the marital relationship.

\section{Discussion}

Being abstract and interpretive, the theoretical comprehension is not gained from linear thinking but from the connections ${ }^{(14)}$. In this sense, the phenomenon "Recognizing domestic violence as a public health problem and the need for management of the care to the woman" emerges from the connections between the categories representing the paradigmatic model, which expresses the context, the causal conditions, the intervening conditions, the strategies, and the consequence regarding what is happening in the study scenario.

The meanings attributed by the professionals to domestic violence reveal the comprehension of their complexity and magnitude. Gender inequality, economic dependence, alcohol and drug use by the partner and/ or their involvement in drug dealing were identified as events related to the occurrence of domestic violence and the permanence of the women in the relationship. The implications for the health of the woman and of the children, the Brazilian National Health Service (SUS), and economic productivity were mentioned as consequences.

Regardless of how it is expressed, the experience of violence triggers physical, psychological and behavioral health problems in women, such as: bruises, burns, and damage related to somatization of the violence experienced, such as hypertension, epigastric pain, headache, miscarriage, anxiety, depression, posttraumatic stress disorder, and suicide attempts ${ }^{(10,15-17)}$.

Exposed to a daily routine of family violence in childhood and youth, children present learning difficulties at school, tending to reproduce the violence to resolve interpersonal conflicts in their social relationships, including marital relationships ${ }^{(10,18)}$. These data corroborate the meanings attributed by the respondents regarding the implications of domestic violence on the lives of the children.

Regarding the implications for economic productivity revealed by the study, it is important to note that physical and/or mental suffering compromises the social and productive development of the woman, being associated with absenteeism and an impact on the working possibilities of the $\operatorname{woman}^{(4)}$, and impacts on the $\mathrm{GDP}^{(6)}$, supporting the understanding of the phenomenon as a public health problem.

Although they demonstrated theoretical knowledge about the subject, the study reveals the difficulty some professionals had in identifying domestic violence as a cause associated with the woman seeking the healthcare service. The lack of preparation for the care was also revealed, including reporting and referrals.

The healthcare professionals often felt unprepared to deal with the feelings that involve the approach to the woman inserted in a context of domestic violence, reflected in the ambiguity between denying the situation and the duty to help the woman.

Studies show that many professionals referred to not knowing the services or their flow, and do not articulate themselves with them, this being a situation that compromises the referrals. Such situations indicate the lack of professional preparation, which has been mentioned in several studies, with an absence of the theme in the undergraduate course being one of the reasons highlighted ${ }^{(10,19-20)}$.

It is important that professionals are prepared to recognize the signs and symptoms related to the experience of violence and exercise sensitive listening to identify their desires. It is the requirements of the women that will direct the professional procedure, which should guarantee care according to the constitutional principles of integrality in order for the woman to be considered in diverse areas of needs. For this, intersectoral articulations are essential. This is because the care to the woman requires knowledge about health services as well as those linked to the legal, police, social, and psychological spheres, and even to the informal support networks ${ }^{(20)}$.

Given the above and considering the role of the FHS in health promotion, studies indicate the need for training of the professionals and development of specific actions for the prevention of harm such as violence ${ }^{(10,21)}$. The need for the organization of the health unit for managing the care to the women in situations of violence was mentioned by the professionals interviewed as a coping strategy for the phenomenon, which includes 
divulgation of the services, intersectoral articulation and trainings of the professionals in the recognition and care to the woman in the context of domestic violence. The partnership with the university and the inclusion of the violence against women subject in the undergraduate curricula were also referred to as strategic.

The inclusion of the theme in the undergraduate curricula, through experience and clinical placements, was suggested as a strategy to overcome this context. Unfortunately, the concern of the training bodies regarding the insertion of the domestic violence theme into the nursing and medicine curricula is still limited, being found in the syllabi of $16 \%$ of the nursing disciplines and $23 \%$ of the medical course disciplines ${ }^{(22)}$. It is noteworthy that the Maria da Penha Law advocates the inclusion of content on gender, and domestic and family violence against women into the school curricula for all education levels(1).

To understand the complexity around domestic violence favors the recognition of the harm and allows the view of violence as a healthcare object to be amplified, prompting the incorporation of attitudes, beliefs and practices that transcend purely technical care ${ }^{(21,23)}$. A practice that has been incorporated into the municipality concerns the experience of multidisciplinary interaction between the professionals of the minimum team and the NASF. The nurses and physicians interviewed said that given the situations of domestic violence they refer the women for psychosocial support from the NASF and that the matrix support favors a broader approach. The NASF is composed of professionals from different areas of knowledge and its practice has reduced the complexity of seeking support for coping with violence for the women ${ }^{(12,24)}$.

However, the respondents complain about the insufficient number of professional psychologists and social workers to meet the requirements of the community, in which the social problems are not limited to violence against women. This situation leads us to question the accountability of Primary Healthcare, the point of entry for the user, in the monitoring of the woman in the levels of care needed so that her requirements are met. This context concerns us, because professional non-intervention hinders the process of empowerment of the women to cope with the phenomenon and violates the assumptions of the SUS, especially with regard to health promotion and disease prevention in the FHS context $^{(24)}$.

Considering the responsibility for the health of the people in its area of coverage, which includes seeking a response independent of its level of complexity, primary healthcare should seek tactics to ensure the care to women in situations of domestic violence, thus respecting the principle of equality.

Public policy must be in accordance with this constitutional principle in order to consider the singularities and specificities of the way of life of these women, of how they become sick, and of having their requirements fulfilled. There is a need to give visibility to gender discrimination - and often race and social class discrimination, in which the women in situations of domestic violence are historically victimized. The National Policy to Combat Violence against Women (Política Nacional de Enfrentamento à Violência contra as Mulheres) advocates the need for policies for the empowerment of women and for the prevention and confrontation of gender discrimination and violence against women ${ }^{(25)}$.

\section{Conclusion}

The phenomenon "Recognizing domestic violence as a public health problem and the need for management of the care to the woman", grasped from the meanings attributed by the professionals working in the FHS, allows us to comprehend the movement of action and interaction surrounding the care to the woman in a situation of domestic violence.

Although the respondents demonstrated an understanding of domestic violence as harm to the public health, the context that emerged indicates the low visibility of domestic violence within the context of the FHS, and the referral of identified cases for psychosocial care at the NASF. Training with a view of domestic violence as a healthcare object is essential, either through contact in the healthcare space, or through the link with the FHS. Especially considering nursing, attention is drawn to the fact that the nurse integrates the minimum team of the FHS and occupies the management positions in the health unit.

The approach of the theme in the professional formation and training spaces in the services will enable better professional preparation for the care to the woman. Hence the need for management of the health units, which require training of the professionals for the recognition of the harm and intersectoral articulation for carrying out referrals. It is believed that the management of the service for the care to women in situations of domestic violence would increase the chances of identifying this harm and the possibilities of the women being helped, contributing to the strengthening of the SUS. 


\section{References}

1. Lei Maria da Penha (BR). Lei n. 11.340/2006. Coíbe a violência doméstica e familiar contra a mulher. Brasília: Presidência da República; 2006.

2. Meyer DE. Teoria e políticas de gênero: fragmentos históricos e desafios atuais. Rev Bras Enferm. 2008;57(1):13-8.

3. Oliveira $\mathrm{KL}$, Gomes R. Homens e violência conjugal: uma análise de estudos brasileiros. Ciênc Saúde Coletiva. 2011;16(5):2401-13.

4. Miranda MPM, Paula CS, Bordin IA. Life-long domestic violence against women: prevalence and immediate impact on health, work, and family. Rev Panam Salud Publica. 2010;27(4):300-8.

5. Junior PCA, Moraes CL. The domestic violence against the elderly within the Family Health Program of Niterói (RJ, Brazil). Ciênc Saude Coletiva. 2010;15:2983-95.

6. Superintendência de Política para Mulheres (SPM) (BR). Violência contra a mulher custa $10 \%$ do PIB brasileiro [Internet]. [acesso 31 out 2012]. Disponível em: http:// www.spm.salvador.ba.gov.br/index.php?option=com_co ntent\&task=view\&id=405\&Itemid=2.

7. Vieira EM, Perdona GSC, Santos MA. Fatores associados a violência física por parceiro íntimo em usuárias de serviço de saúde. Rev Saúde Pública. 2011;45(4):730-7.

8. Borsoi TS, Brandão ER, Cavalcanti, MLT. Ações para o enfrentamento da violência contra a mulher em duas unidades de atenção primária à saúde no município do Rio de Janeiro. Interface. 2009;13(28):165-74.

9. Gomes NP, Diniz NMF, Silva CC Filho, Santos JNB. Enfrentamento da violência doméstica contra a mulher a partir da interdisciplinaridade e intersetorialidade. Rev Enferm UERJ. 2009;17(1):14-7.

10. Gomes NP. Trilhando caminhos para o enfrentamento da violência conjugal [tese]. Salvador: Universidade Federal da Bahia; 2009.

11. Ferraz MIR, Lacerda MR, Labronici LM, Maftum MA, Raimondo ML. O Cuidado De Enfermagem a Vítimas de Violência Doméstica. Cogitare Enferm. 2009;14(4): 5-17. 12. Superintendência de Políticas para Mulheres (SPM) (BR). Balanço semestral do ligue 180 (janeiro à junho/2012). Brasília: Presidência da República; Secretaria de Políticas para Mulheres; 2012.

13. Strauss A, Corbon J. Pesquisa qualitativa: técnicas e procedimentos para o desenvolvimento de teoria fundamentada. Porto Alegre: Artmed; 2008. 288 p.
14. Charmaz K. A construção da teoria fundamentada: guia prático para análise qualitativa. Porto Alegre: Artmed; 2009. 272 p.

15. Ministério da Saúde (BR). Secretaria de políticas para as mulheres. Balanço central de atendimento à Mulher [Internet]. 2010. [acesso $1 \mathrm{dez}$ 2011]. Brasília: Editora do Ministério da Saúde; 2010. Disponível em: http:// www.sepm.gov.br/noticias/ultimas_noticias/2010/10/ balanco-da-central-de-atendimento-a-mulher.

16. Taft CT, Resick PA, Watkins LE, Panuzio J. An investigation of posttraumatic stress disorder and depressive symptomatology among female victims of interpersonal trauma. J Familiar Violence. 2009;24:407-15. 17. Guedes RN, Silva ATMC, Fonseca RMGS. The violence of gender and health-disease process of women. Esc Anna Nery. 2009;13(3):625-31.

18. Gomes NP, Diniz NMF. Experiencing familiar violence: men who commit violence against their mates. Rev Bras Enferm. 2005;58(2):176-9.

19. Tomaz SNM, Galvão LLLF, Melo COM, Azevedo GD. Violencia física contra la mujer en la perspectiva de profesionales de la salud. Rev Saúde Pública. 2008;42(6): 1053-9.

20. Santi LN, Nakano AMS, Lettiere A. Domestically abused Brazilian women's perceptions about support and received support in its social context. Texto Contexto Enferm. 2010;19:417-24.

21. Minayo MCS, Souza ER. Is it possible to prevent violence? Reflections in public health area. Ciênc Saúde Coletiva. 1999;4(1):7-32.

22. Souza ER, Penna LHG, Ferreira AL, Tavares CMM, Santos NC. O tema violência intrafamiliar em currículos de graduação em enfermagem e medicina. Rev Enferm UERJ. 2008;16(1):13-9.

23. Carneiro AA, Fraga CK. Maria da Penha's Law and the legal protection to women who are victims in the city of São Borja (Rio Grande do Sul): from reported violence to violence silenced. Serv Social Soc. 2012;(110):369-97.

24. Andrade CJM, Fonseca RMGS. Considerações sobre violência doméstica, gênero e o trabalho das equipes de saúde da família. Rev Esc Enferm USP. 2008;42(3):591-5. 25. Superintendência de Políticas para as Mulheres (SPM) (BR). Politica nacional de enfrentamento à violência contra a mulher. Brasília: Secretaria Nacional de Enfrentamento à Violência contra as Mulheres; Secretaria de Políticas para as Mulheres; 2011. 